\title{
Pediatric gastroenterology - are you kidding?
}

\author{
Kevan Jacobson MBBCh FRCPC ${ }^{1}$, Paul C Adams MD FRCPC ${ }^{2}$, Editor-in-Chief
}

K evan Jacobson is an Associate Professor of pediatrics at the University of British Columbia, Vancouver, British Columbia. He has training as an adult and pediatric gastroenterologist.

PA: What is a pediatric gastroenterologist?

$\mathrm{KJ}$ : A pediatric gastroenterologist is defined as a physician who either has Royal College certification in pediatric gastroenterology or is affiliated with an academic division of pediatric gastroenterology in a university setting.

PA: How many training programs are there in Canada? Is there any demand for these training programs?

KJ: There are six Royal College-accredited gastroenterology fellowship training programs and one nonaccredited training program. While we have no specific figures on the number of Canadian applicants to Canadian pediatric gastroenterology fellowship programs each year, it does appear that the number of Canadian applicants entering Canadian pediatric gastroenterology fellowship programs has decreased. The precise reason for this has not been determined. Factors likely to account for this decline include the lack of secure funding

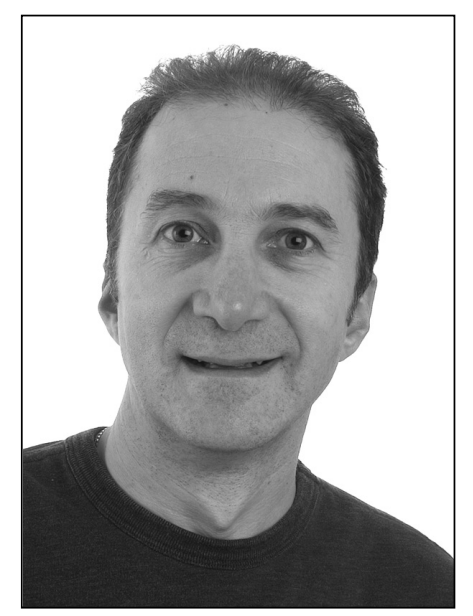

Kevan Jacobson is an Associate Professor of pediatrics at the University of British Columbia. He has training as an adult and pediatric gastroenterologist the overall approach to the evaluation of pediatric patients of varying ages and their families; the spectrum of disease in children; the need to adapt diagnostic tests and interventions to the age-specific needs of the pediatric patient; and the attention to therapeutics in the pediatric age groups, especially with regard to mode of delivery, side effect profiles and longterm implications. Children are not small adults, which is why the Royal College and other examining boards in America and elsewhere have developed pediatric subspecialty training programs and certification.

PA: Does the treatment of common GI diseases differ much between children and adults? KJ: While the choice of therapies is similar, the pharmacokinetics, pharmacodynamics and medication delivery systems (suspension versus pill) are age specific. Moreover, consideration must be given to the effect of therapeutics on growth and development. Many of the current therapies used in adults have not been formally approved for use in children. This is particularly relevant for novel agents such as infliximab, for which the potential for longterm side effects are unknown.

PA: Are there reimbursement issues that in Canadian programs for Canadian pediatric gastroenterology trainees; the attraction of larger American programs with more secure funding; and a reduction in residents choosing to enter a gastrointestinal (GI) fellowship program because, unlike in the adult world, pediatric gastroenterologists in Canada are mostly restricted to working in academic centres. In Canada, private office practice or working in the periphery is generally nonviable and not financially realistic for subspecialists in our field. Finally, there may be a general disinterest of pediatric residents choosing subspecialty training. Many pediatric residents wish to complete training in three to four years and enter the workforce.

On the other hand, international trainees are highly attracted to Canadian pediatric gastroenterology fellowship programs, making up over $50 \%$ of the training pool. Between 1998 and 2006, of the 65 fellows trained in Canadian pediatric gastroenterology fellowship programs, 65\% were international trainees.

PA: How does pediatric gastroenterology differ from adult gastroenterology in the general community?

KJ: This is an existential question. How does internal medicine differ from pediatrics? The important distinctions include favour adult gastroenterology?

KJ: Yes. Reimbursements are generally based on the number of patients seen and diagnostic procedures performed. Pediatric gastroenterology consultations usually require more time, because the assessment involves both patient and family. Moreover, interventional procedures in pediatrics generally take longer to perform because of extra time needed for sedation and recovery.

A Pediatric Subspecialty Workforce analysis that was published in 2005 (1) noted financial disparities between adult and pediatric subspecialists in terms of compensation and reimbursement for services provided. Furthermore, a recent American physician compensation survey (2) highlighted that despite the same number of years of training, the pediatric gastroenterologist's starting salary lags by more than US $\$ 100,000$. PA: Should adult gastroenterologists be performing endoscopy in children when there are no pediatric gastroenterologists?

$\mathrm{KJ}$ : As a rule, the answer is no. Of course, this would depend on the age and maturity of the child in question. A rule of thumb to follow is that the further away the child is from adult age and maturity, the greater the need for pediatric

\footnotetext{
${ }^{1}$ Department of Pediatrics, British Columbia Children's Hospital, University of British Columbia, Vancouver, British Columbia; ${ }^{2}$ University Hospital, London, Ontario

Correspondence: Dr Kevan Jacobson, 4480 Oak Street, Room K4-181, Vancouver, British Columbia V6H 3V4. Telephone 604-875-2332, fax 604-875-3244, e-mail kjacobson@cw.bc.ca
} 
expertise. There are published data (3-5) indicating that pediatric procedures are more optimally performed in a pediatric setting with trained pediatric personnel. Another important consideration is that the adult gastroenterologist who chooses to perform an endoscopic procedure on a child must also feel comfortable managing the child.

PA: Would a rotation in pediatric gastroenterology be of benefit in an adult gastroenterology training program?

$\mathrm{KJ}$ : Yes, this should be mandatory. A rotation through pediatric gastroenterology provides a pediatric perspective and increases awareness of the differences in management of pediatric patients. We also believe that the reverse exchange should apply, in which pediatric gastroenterology fellows rotate through adult gastroenterology programs. This approach increases understanding of the differences in practice, enhances collaboration and improves transition of care.

PA: What are the challenges of the future?

$\mathrm{KJ}$ : The Canadian pediatric gastroenterology community is of the opinion that the current Canadian pediatric gastroenterology workforce is inadequate to meet present demands. With the limited number of Canadian trainees entering fellowship programs, the changing demographics, with an increasing number of females entering the workforce and altered job profiles, along with the aging current pediatric GI cohort, there is concern that the workforce will not meet pediatric population GI health care demands in the next decades.

\section{REFERENCES}

1. Jewett EA, Anderson MR, Gilchrist GS. The pediatric subspecialty workforce: Public policy and forces for change. Pediatrics 2005;116:1192-202.

2. Cejka Search. 2006 American Medical Group Association compensation survey. <http://www.cejkasearch.com/compensation/ amga_physician_compensation_survey.htm $>$ (Version current at September 12, 2007).

3. Eisen GM, Chutkan R, Goldstein JL, et al. Modifications in endoscopic practice for pediatric patients. Gastrointest Endosc 2000;52:838-42.

4. Cote CJ, Notterman DA, Karl HW, Weinberg JA, McCloskey C. Adverse sedation in pediatrics: A critical incident analysis of contributing factors. Pediatrics 2000;105:805-14.

5. King WK, Stockwell JA, DeGuzman MA, Simon HK, Khan NS. Evaluation of a pediatric-sedation service for common diagnostic procedures. Academic Emerg Med 2006;13:673-6. 


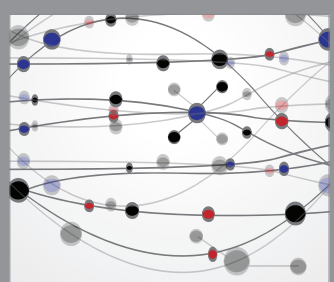

The Scientific World Journal
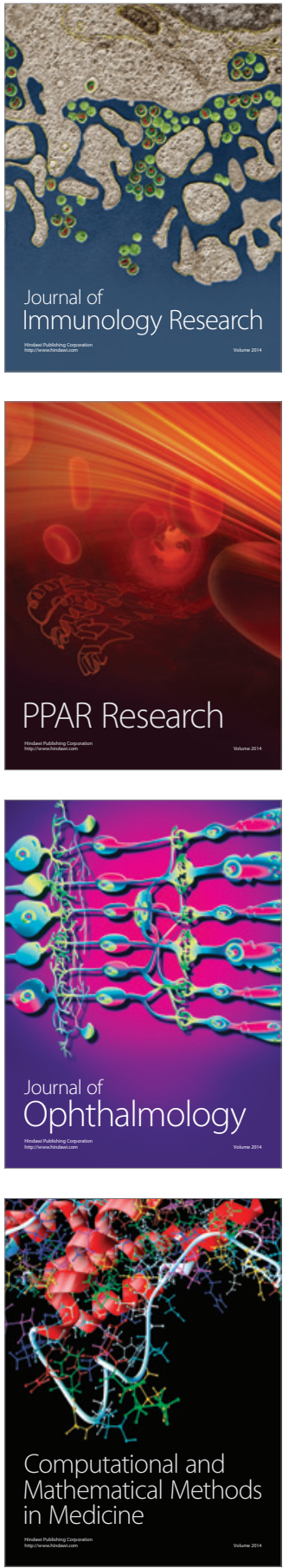

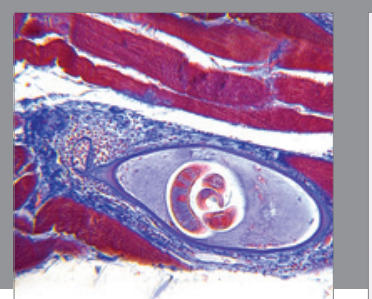

Gastroenterology Research and Practice

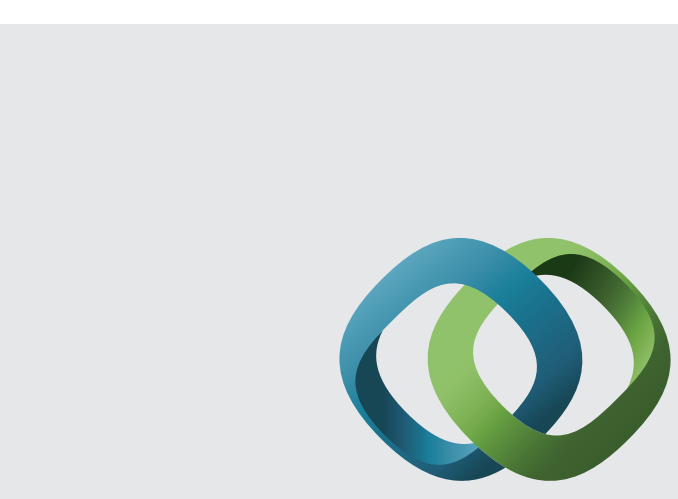

\section{Hindawi}

Submit your manuscripts at

http://www.hindawi.com
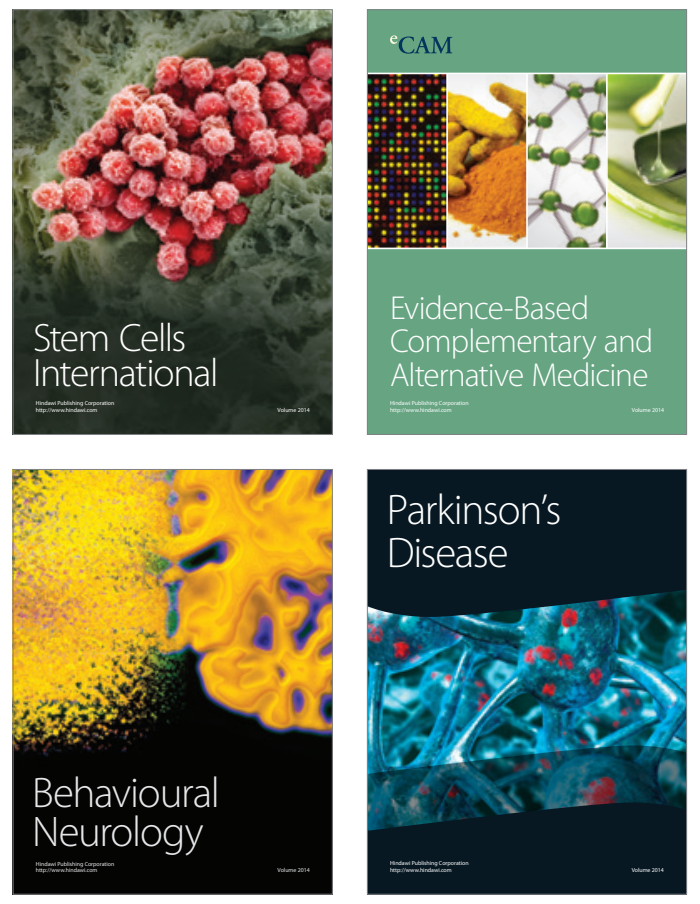
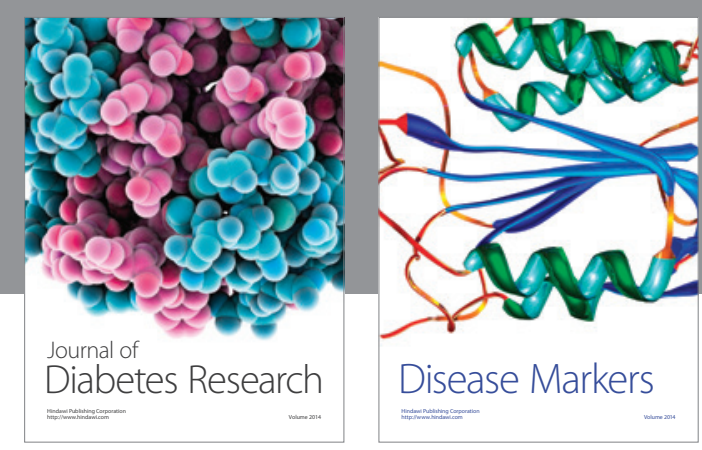

Disease Markers
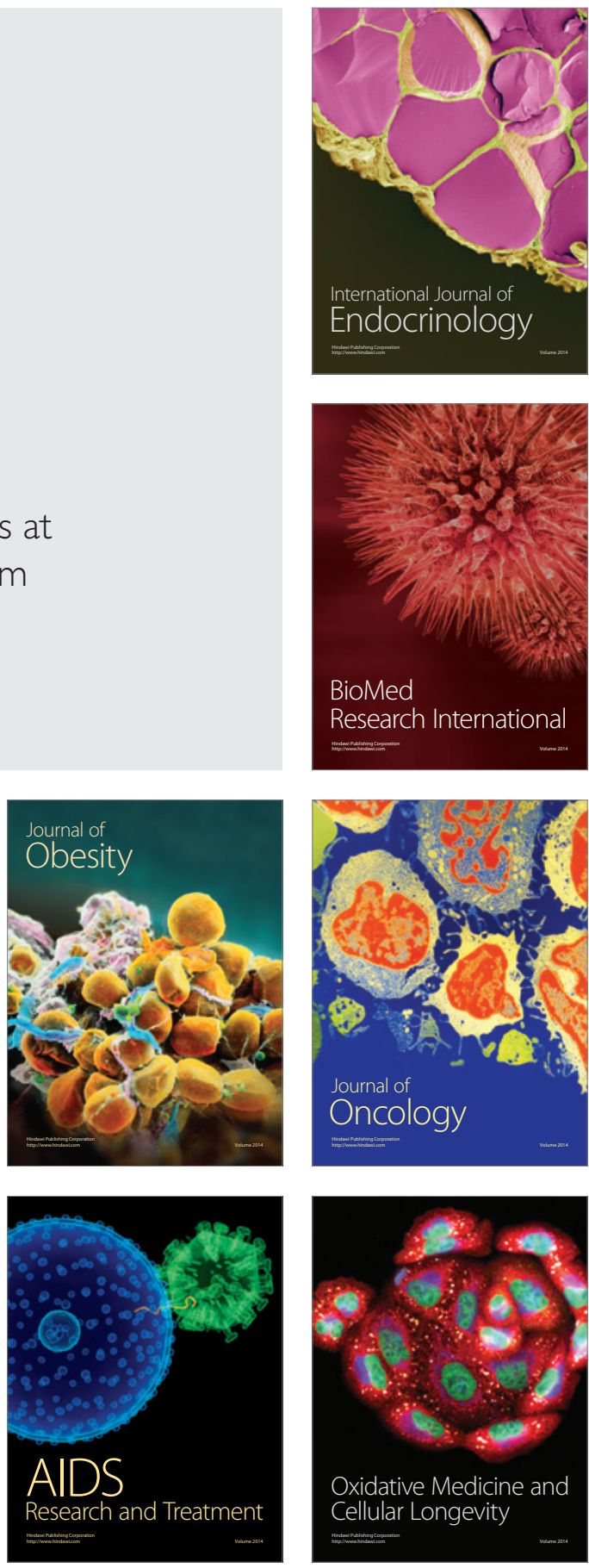